J. Lake Sci. (湖泊科学), 2012, 24(3): 443-449

http: //www.jlakes.org. E-mail : jlakes@niglas.ac.cn

(C) 2012 by Journal of Lake Sciences

\title{
梯级水坝胁迫下东江鱼类产卵场现状分析"
}

\author{
谭细畅, 李跃飞, 李新辉**, 李 捷, 王 超 \\ (中国水产科学研究院珠江水产研究所,广州 510380)
}

\begin{abstract}
摘 要: 东江作为珠江流域重要支流之一, 是香港地区以及珠江三角洲东部地区重要水源. 鱼类不仅是河流生态系统重 要组成也是其健康状况的重要指示生物. 目前东江已经修建了一系列水坝, 基于东江河流生态系统健康维持和管理的需 要, 有必要了解河流中鱼类产卵场的现状. 据此,2010 年 3-10月对东江古竹江段的鱼苗 (卵) 进行了连续采集, 目前鱼苗 种类已鉴定到 26 种 (属), 主要优势种类为鰕鯱 (63.0\%)、赤眼䲡 $(16.8 \%$ )、尼罗罗非鱼 $(9.7 \%$ )、大眼鳇 $(2.0 \%)$ 等; 调 查期间古竹江段鱼苗 (卵) 径流量初步估算为 $11.4 \times 10^{8}$ 尾(颗), 东江鱼类主要繁殖期为 4-9 月. 与东江历史资料及西 江江段鱼类繁殖现状相比较, 东江鱼类产卵场功能极度退化, 不仅鱼类产卵规模已明显下降, 并且东江古竹江段鱼苗中 洄游性种类缺失; 本次调查证明东江龙川江段原有的四大家鱼产卵场已经消失; 通过典范对应分析分析表明, 东江江段 鱼类产卵繁殖对水文生态因子的响应程度较低, 说明东江江段水文节律受梯级水坝影响程度大, 偏离了鱼类产卵繁殖的 生态需求. 尼罗罗非鱼在东江古竹江段有暴发性繁殖现象, 东江已经面临外来种的严峻威胁, 分析认为梯级水坝的修建 是导致罗非鱼暴发性增长的主要原因之一. 根据目前东江鱼类产卵场现状, 建议把鲢、鳙及广东鲂列人增殖放流的品种 目录, 加强人工增殖放流; 从贯通鱼类洄游通道及修复产卵场的需求上考虑, 建议在东江各水坝上补建鱼类过鱼通道.
\end{abstract}

关键词: 鱼类产卵场; 东江; 梯级水坝; 胁迫;古竹段

\section{The status of fish spawning ground in the East River with cascade dams' duress}

\author{
TAN Xichang, LI Yuefei, LI Xinhui, LI Jie \& WANG Chao \\ (Pearl River Fishery Research Institute, Chinese Academy of Fishery Sciences, Guangzhou 510380, P. R. China)
}

\begin{abstract}
As the eastern tributary of the Pearl River in Guangdong Province, southern China, East River is a major source of water supply for Hong Kong and Shenzhen. Besides their important role in nutrient cycling and transformation in the river ecosystem, fish are also considered as good indicators of aquatic ecosystem health. For the purposes of assessment and management of East River it is necessary to look into the status of fish spawning ground, especially with cascade dams' duress. From March to October, 2010, we studied taxonomic composition and daily variation of fish larvae abundance from a survey in the Guzhu section of East River over a period of 8 months, and collected 26 species (or genera). The fish larval samples were numerically dominated by four species, Gobies (Gobiidae) 63.0\%, Barbel Chub (Squaliobarus curriculus) 16.8\%, Tilapia (Tilapia mossambica) 9.7\% , and Mandarin (Siniperca kneri) $2.0 \%$. These four species accounted for $91.5 \%$ of total numbers. During the sampling period, the total fish larvae abundance was estimated as 1.14 billion. When compared with historical records from the $1950 \mathrm{~s}$ ' and the currently condition of fish larvae in the West River, there are obvious degradation in the fish larvae community in East River, which means no migratory species and irregular response to the hydrological variation. It comes to the conclusion that the cascade dams blocked the fish migration and caused the disappearing of some spawning grounds. Our results clearly show that Tilapia larvae outbreak in the East River, which is very dangerous to the ecology safety. We also conclude that construction of cascade dams makes the East River more habitable for Tilapia. For the purpose of protecting ecosystem , we recommend that more Silver Carp (Hypophthalmichthys molitrix), Bighead Carp (Aristichthys nobilis) and Black Guangdong Bream (Megalobrama terminalis) be released to the East River and possibly constructions of fish passage be considered.
\end{abstract}

Keywords: Fish spawning ground; East River; cascade dams; duress; Guzhu section

* 国家水体污染控制与治理科技重大专项项目 (2009ZX07211-009) 资助. 2011-07-26 收稿;2012-01-04 收修改 稿. 谭细畅, 男, 1973 年生, 博士, 副研究员; E-mail:jimtxc@ hotmail. com.

** 通信作者; E-mail:1xhui01@ tom. com. 
东江是珠江流域三大河流之一, 干流全长 $562 \mathrm{~km}$, 年平均水资源总量为 $331.1 \times 10^{8} \mathrm{~m}^{3}$, 是香港地区以 及珠江三角洲东部地区重要水源. 根据 1982-1983 年调查结果, 东江有鱼类 131 种,占珠江水系鱼类 385 种 的 $34 \%{ }^{[1]}$. 历史上东江盛产洄游性、半洄游性鱼类如鲋鱼、花鮊、七丝鲚、四大家鱼等,每年 $4-6$ 月, 鲥鱼、花 䰻溯河洄游至新丰江形成鱼汛. 1960s 以后, 东江下游 8 个河口中有 5 个陆续修建了防咸潮水闸, 干流和支 流也兴建了新丰江水库等水利工程,鲋鱼、花鮊的数量大大减少. 2003 年东江干流水电梯级的大规模开发建 设, 枫树坝以下江段完成建设的水电站有 10 个,1 个在建(图 1). 近年来, 东江的鱼类资源状况颇受关注, 各 个江段的鱼类群落结构都有相关文献报道, 调查采集到的种类上游达 49 种, 中下游则达 98 种, 其中明显变 化是洄游性种类数量减少, 如三线舌鳎、弓斑东方鲀、鳗鲡、花䱕、七丝鲚等 ${ }^{[24]}$.

水坝使自然河流非连续化, 显著改变了其原有水动力条件, 对鱼类最直接的影响是阻隔了洄游通道, 对 生活史过程中需要洄游的种类影响则可能是毁灭性的,即使在局部水域内能完成生活史的种类,生境破碎 也会导致其种群遗传多样性丧失等. 因此,水坝对鱼类产卵场的影响一直颇受关注. 周春生等 ${ }^{[5]}$ 对汉江水利 枢纽建成后漂流性卵鱼类的繁殖状况进行了研究; 余志堂等 ${ }^{[6]}$ 在葛洲坝枢纽截流后对长江干流四大家鱼产 卵场的分布和规模等进行了细致地调查. 近几年, 亦有不少针对江河中鱼类产卵繁殖情况的调查, 如李修峰 等 ${ }^{[7]}$ 对汉江中游产漂流性卵鱼类产卵场的现状进行调查; 谭细畅等 ${ }^{[8-11]}$ 及李跃飞等 ${ }^{[12]}$ 对珠江水系西江的鱼 类早期资源现状进行调查, 段辛斌等 ${ }^{[13]}$ 对三峡水库蓄水后长江中游产漂流性卵鱼类产卵场现状进行调查. 在其它国家,针对水坝胁迫下鱼类产卵场的现状也有许多研究,如 Paukert 等 $^{[14]}$ 对美国俄克拉荷马州 Kaw 水坝上的匙吻鲟鱼苗进行调查以研究其生殖洄游; Rogério 等 ${ }^{[15]}$ 对巴西 Uruguary 河上游 3 个支流的鱼卵、鱼 苗的分布与数量进行了调查, 以了解支流的产卵场功能.

东江的鱼类产卵场状况历史背景资料甚为缺少,过去大体情况是, 河源龙川江段曾分布有四大家鱼产卵 场 ${ }^{[16]}, 1950 \mathrm{~s}$ 东江四大家鱼鱼苗年捕捞量达 $2 \times 10^{8}$ 尾 $^{[1]}$. 目前随着水坝在东江的逐渐增多及其它环境胁迫的 日益加剧, 迫切需要了解东江鱼类产卵场的现状, 以便深人分析东江江段鱼类群落变动趋势及采取必要的 保护措施,维系东江河流生态系统健康和水资源的生态安全. 因此为了解东江鱼类产卵现状, 2010 年 3-10 月,在古竹江段设置了鱼苗、鱼卵监测点,进行连续采样,并在样品整理、鉴定的基础上分析了鱼类产卵繁殖 与水文因子关联性, 以期为东江的鱼类资源保护、河流管理、生态修复提供基础性数据.

\section{1 材料与方法}

\section{1 采样网具}

采样网具为弶网, 网口为长方形 $(1 \mathrm{~m} \times 1.5 \mathrm{~m})$, 网长 $4 \mathrm{~m}$, 由前向后逐渐变细, 与集苗箱 $(0.8 \mathrm{~m} \times 0.4 \mathrm{~m} \times$ $0.4 \mathrm{~m})$ 连接,收集鱼苗. 集苗箱以密封的 PVC 塑料管浮于水面,网衣由网目为 $0.776 \mathrm{~mm}$ 的篎绢制成.

\section{2 采样地点与时间}

采样地点位于古竹镇东江大桥上 $1 \mathrm{~km}$ 处, 距离河源市区下约 $40 \mathrm{~km}$, 距离紫金县临江镇水坝约 $14 \mathrm{~km}$, 下游距离惠州剑潭水利枢纽尾水区约 $66 \mathrm{~km}$ (图 1). 采样日期为 2010 年 3 月 18 日至 10 月 31 日,采样时间 段为 $19: 00-21: 00$, 持续时间 $2 \mathrm{~h}$.

样品用 $5 \%$ 福尔马林液固定后运回实验室进行镜检. 网口流速测定采用重庆水文仪器厂生产的旋杯式 流速仪.

\section{3 样品鉴定及数据分析}

在解剖镜下根据体形、肌节数、色素形态、鯺(褶) 形态、眼相对大小和位置等特征进行种类识别. 鉴定主 要依据曹文宣等 ${ }^{[17]}$ 、易伯鲁等 ${ }^{[18]}$ 及梁秩焻 ${ }^{[19]}$ 对鱼类的早期发育特征的描述.

鱼苗径流量计算公式为: $M=[m /(s \cdot v)] Q$,式中, $M$ 为鱼苗总数 (ind. ), $Q$ 为采集点断面的江水流量 $\left(\mathrm{m}^{3} / \mathrm{s}\right), v$ 为流经网口的江水流速 $(\mathrm{m} / \mathrm{s}), m$ 为采集到的鱼苗数量 (ind.), $s$ 为网口面积 $\left(\mathrm{m}^{2}\right)$, 总鱼苗径流量 用单位时间鱼苗径流量换算得出.

通过典范对应分析 (Canonical Correspondence Analysis, CCA ${ }^{[20]}$ 分析古竹江段鱼苗 (卵) 总量、鱼卵量及 主要优势种类数量与水文环境因子径流量、气温、水温、气压、降雨量的关系. 水温通过 HOBO 水温记录仪每 天自动测定保存,古竹江面断面流量数据来自全国水文信息网 (http://xxfb. hydroinfo. gov. cn) 及广东水文信 
息网 (http://www. gdsw. gov. cn), 气象数据来自气象在线网 (www. qxzx. cn).

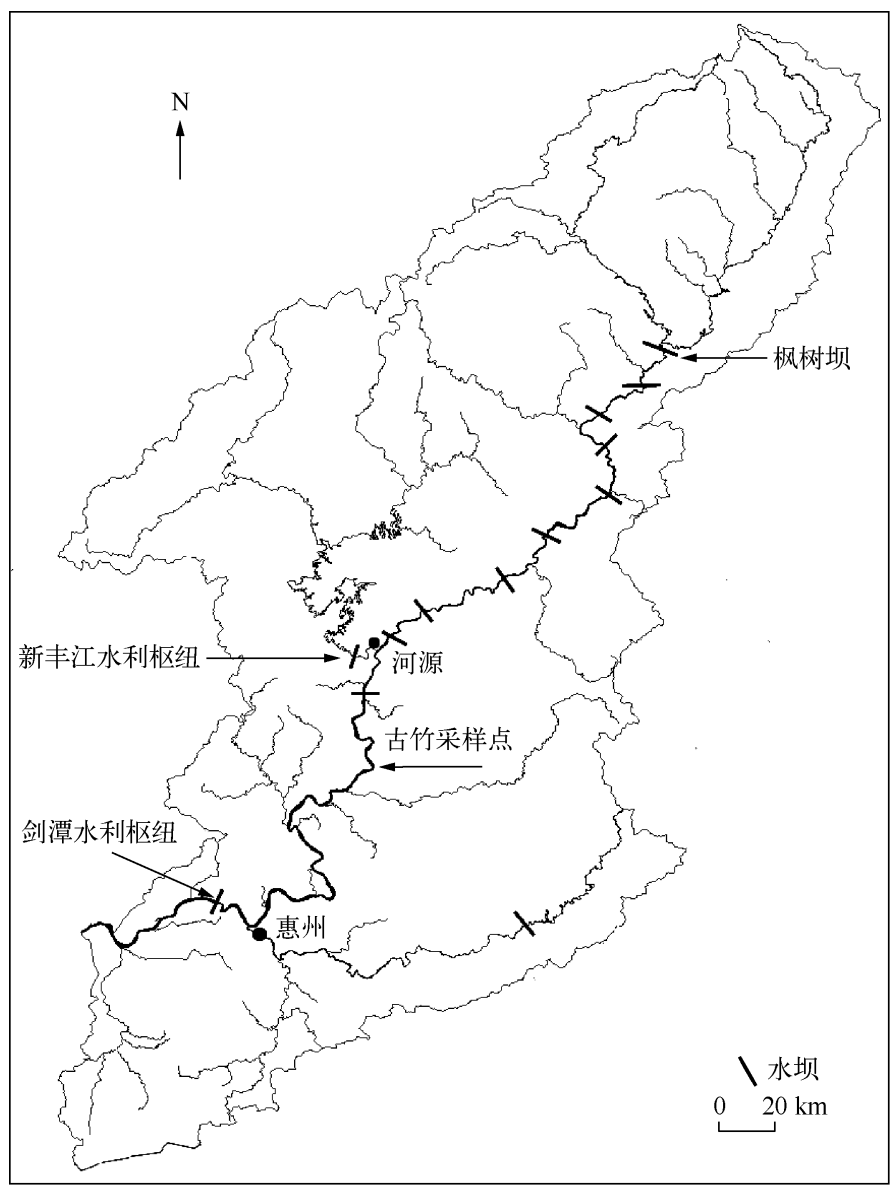

图 1 东江水系主要水坝的分布以及鱼苗采样点位置

Fig. 1 Distribution of dams and fish larvae sampling site in the East River

\section{2 结果与分析}

\section{1 鱼苗种类组成}

根据东江古竹江段 3-10 月份采集样品,共鉴定出鱼苗种类 26 类(种或属) (表 1). 数量上主要优势种 类为鰕鯱类 $63.0 \%$ 、赤眼鳟 $16.8 \%$ 、尼罗罗非鱼 $9.7 \%$ 、大眼鳜 $2.0 \%$ 、高体鰟鮍 $1.2 \%$ 、餐 $1.7 \%$ 、鲖类 $1.2 \%$ 、红鲌类 $1.1 \%$ 、银鮈 $1.0 \%$ 、纵带鯔 $0.8 \%$ 等; 其它一些种类为鲤、鲫、白肌银鱼、中华花鱾、泥鳅、福建 纹胸鮡、食蚊鱼等. 其它的 $5 \sim 7$ 种待进一步鉴定, 但这些种类数量比例很小.

\section{2 鱼类产卵规模状况}

根据 3-10 月份样品统计, 古竹江段鱼 (卵) 占采集到的苗卵数量的 $71 \%$; 古竹江段鱼卵的发育期主要 为囊胚晚期与尾芽期, 分别占 35\% 和 65\%, 距离产卵受精时间约为 $8 \mathrm{~h}$ 及 $20 \mathrm{~h}$. 水流流速以 $0.75 \mathrm{~m} / \mathrm{s}$ 估算, 该时期古竹江段的鱼卵主要来源于上游 $21 \sim 54 \mathrm{~km}$ 的河源江段, 35\% 的鱼卵来源于临江坝与木京坝间江段, $65 \%$ 的鱼卵来源于木京坝与黄田坝之间江段. 3 月下旬至 10 月底, 古竹江段鱼苗 (卵) 径流量初步估算为 $11.4 \times 10^{8}$ 尾(颗), 鱼类主要繁殖期在 4-9 月 (图 2a).

从 4 月份开始, 古竹江段有多次涨水, 但 7-8 月份几乎没有明显的洪峰出现 (图 2b), 相应该时期也没 有较大规模的鱼类产卵繁殖活动. 
表 1 东江古竹江段已鉴别鱼苗种类

Tab. 1 Species of ichthyoplankton in Guzhu section of the East River

\begin{tabular}{|c|c|c|}
\hline 目 & 科 & 种类 \\
\hline 鲑形目 Salmoniformes & 银鱼科 Salangidae & 白肌银鱼 Leucosoma chinensis Osbeck \\
\hline \multirow[t]{16}{*}{ 鲤形目 Cypriniformes } & 鲤科 Cyprinidae & 赤眼䲡 Squaliobarus curriculus Richardson \\
\hline & & 红鲌属 Erythroculter Berg \\
\hline & & 餐 Hemiculter leucisculus Basilewsky \\
\hline & & 飘鱼属Pseudolaubuca Bleeker \\
\hline & & 鲖属 Xenocypris Günther \\
\hline & & 鲮 Cirrhina molitorella Cuvier et Valenciennes \\
\hline & & 高体鳑鲏 Rhodeus ocellatus Kner \\
\hline & & 银鮈 Squalidus cephalus Linnaeus \\
\hline & & 四须盘鮈 Discogobio tetrabarbatus Lin \\
\hline & & 鲤 Cyprinus carpio Linnaeus \\
\hline & & 鲫 Carassius auratus Linnaeus \\
\hline & & 条纹小鲃 Puntius semifasciolatus Günther \\
\hline & 鳅科 Cobitidae & 中华花鳅 Cobitis sinensis Sauvage et Dabry \\
\hline & & 美丽小条鳅 Micronemacheilus pulcher Nichols et Pope \\
\hline & & 泥鳅 Misgurnus anguillicaudatus Cantor \\
\hline & & 花斑副沙鳅 Parabotia fasciata Dabry \\
\hline \multirow[t]{3}{*}{ 鲇形目 Siluriform } & 鲇科 Siluridae & 鲇 Silurus asotus Linnaeus \\
\hline & 鲿科 Bagridae & 纵带鯔 Leiocassis argentivittatus Regan \\
\hline & 鮡科 Sisoridae & 福建纹胸鮡 Glyptothorax fokiensis Rendahl \\
\hline 鲟形目 Cyprinodontiformes & 食蚊鱼科 Pocciliidae & 食蚊鱼 Gambusia affinis Baid et Giraad \\
\hline \multirow[t]{5}{*}{ 鲈形目 Perciformes } & 鮨科 Serranidae & 大眼鳜 Siniperca kneri Garman \\
\hline & 丽鱼科 Cichlidae & 尼罗罗非鱼 Tilapia nilotica Linnaeus \\
\hline & 鰕虎鱼科 Gobiidae & 鰕鯱 Rhinogobius \\
\hline & 塘鳢科 Eleotridae & 塘鳢 Eleotris \\
\hline & 鳢科 Channidae & 大刺鳅 Mastacembelus armatus Lacépède \\
\hline
\end{tabular}
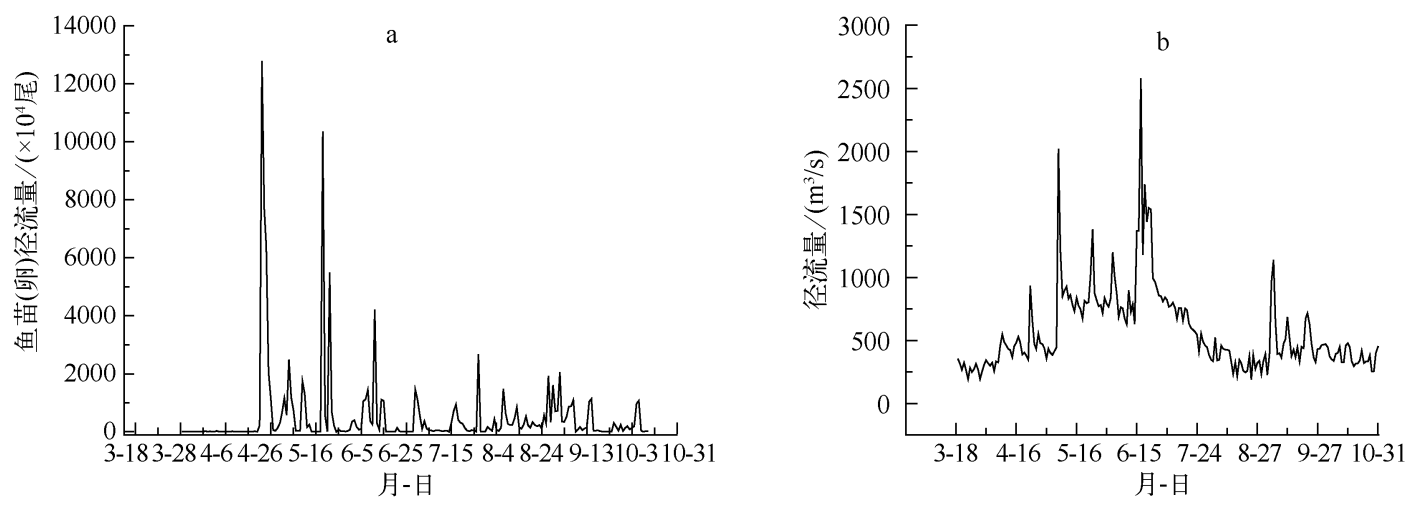

图 2 古竹江段鱼苗(卵)径流量 (a) 和径流量 (b) 日变化(2010 年 3-10 月)

Fig. 2 Dynamic of total ichthyoplankton amount (a) and discharge (b) in the Guzhu section of the East River

from March to October, 2010 


\section{3 尼罗罗非鱼自然繁殖状况}

在东江古竹江段, 尼罗罗非鱼苗主要出现 在 7-10 月, 峰值出现在 10 月 1-6 日 (图 3). 尼罗罗非鱼在鱼苗中的比例约占 $9.7 \%$, 在繁 殖高峰期, 单位网次采集量最高达 880 尾, 数 量比例达 $85 \%$, 呈现暴发性增长. 2010 年 510 月, 在鱼苗样品中, 罗非仔稚鱼共计 2086 尾, 体长范围 $8.27 \sim 13.40 \mathrm{~mm}$, 均值 $9.40 \mathrm{~mm}$; 采集到的罗非鱼苗形态发育一般在鯺条形成 期之后, 但 10 月 5-6 日发育时序主要有卵 $(11.8 \%)$ 、卵黄未吸尽 $(67.5 \%)$ 、卵黄吸尽 (20.7\%). 参照易伯鲁等 ${ }^{[18]}$ 对鱼苗径流量的 计算方法,初步估算 2010 年 3-10 月,在东江 古竹江段罗非鱼苗径流量达 $2294 \times 10^{4}$ 尾.

\section{4 鱼类繁殖与水文因子关联性分析}

通过 CCA 分析古竹江段鱼苗 (卵) 总量、 鱼卵量及主要优势种类数量与水文环境因子 径流量、气温、水温、气压、降雨量关系. CCA 二 维排序图结果表明, 总体上鱼类的产卵繁殖与 径流量、水位变动有较强关联性, 但不同的鱼类 产卵繁殖对水文环境因子的生态需求存在差异 性, 其中鰕鯱鱼类、䱗与水温关联较明显, 而赤 眼鯂、红鲌属鱼类对水温及径流量生态需求则 不大 (图 4). 不同水文生态因子与 CCA 排序轴 关系系数见表 2 .

\section{3 讨论}

\section{1 鱼类产卵现状比较分析}

与东江历史数据及西江目前鱼类繁殖状况 相比较, 东江鱼类产卵场功能严重退化. 历史 上, 东江四大家鱼鱼苗年捕捞量达 $2.0 \times 10^{8}$ 尾 $^{[1]}$, 因为人工装捞的鱼苗仅河流中很小部分, 总鱼苗径流量每年可能高达上千亿尾; 而目前 东江古竹江段主要繁殖期鱼苗总径流量仅 11.4 $\times 10^{8}$ 尾, 相比之下鱼类产卵量极度下降, 鱼类 资源状况极度衰竭.

尽管鱼苗种类上有 26 种, 但其优势种为鰕 鯱类、赤眼鳟、尼罗罗非鱼、䱗等, 缺失洄游 (半 洄游) 的种类, 如七丝鲚、青鱼、草鱼、鲢、鳙等,

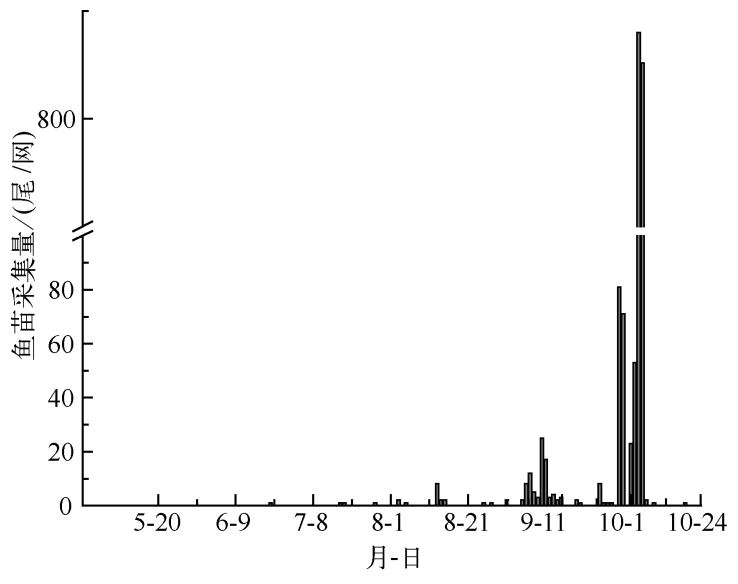

图 3 古竹江段尼罗罗非鱼苗(卵)断面流量日变化 (2010 年 5-10月)

Fig. 3 Dynamic of total Tilapia amount in the Guzhu section of the East River from May to October, 2010

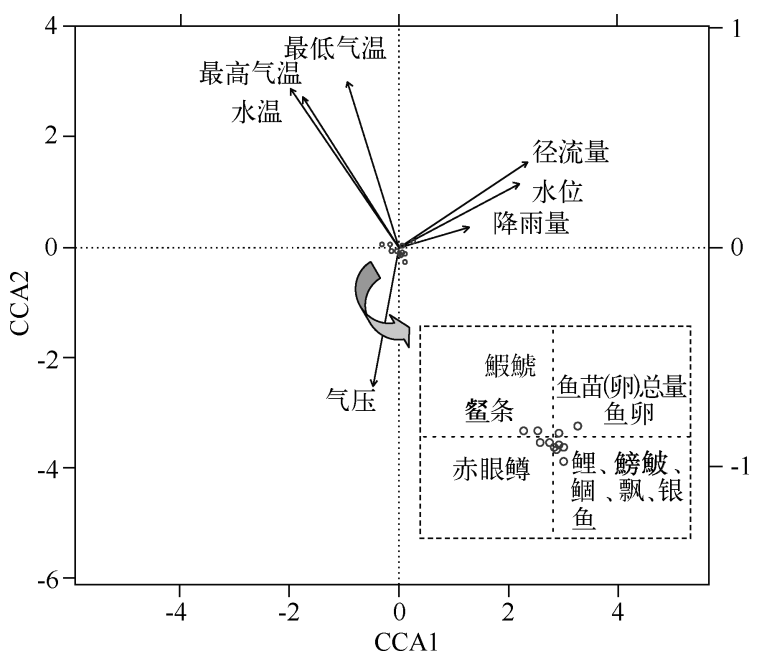

图 4 古竹江段鱼类繁殖与水文生态因子的 典范对应分析二维排序图

Fig. 4 Plot of results of canonical correspondence analysis showing the relation of fish larvae species with the environmental variables on the two canonical axes in the Guzhu section of the East River 说明梯级水坝阻隔了鱼类的洄游通道, 导致其产卵场消失, 鱼类资源严重衰退, 这与东江近年的鱼类捕捞状 况调查结果 ${ }^{[2-4]}$ 相吻合. 与肇庆江段鱼苗资源调查结果 ${ }^{[10]}$ 相比较, 东江古竹江段的鱼苗种类较为单一. 在古 竹江段没有采集到四大家鱼的鱼苗, 说明目前东江中上游家鱼产卵场基本上已经消失; 另外在古竹江段也 没有采集到广东鲂 (Megalobrama terminalis) 的鱼苗, 呈现出与西江江段在鱼类早期资源种类结构上的明显 差异. 
表 2 古竹江段不同水文生态因子与前 CCA 排序轴关系系数

Tab. 2 Summary of canonical correspondence analysis with the environmental variables in the Guzhu section of the East River

\begin{tabular}{crrrrrr}
\hline 指标 & CCA1 & CCA2 & CCA3 & CCA4 & CCA5 & \multicolumn{1}{c}{ CCA6 } \\
\hline 径流量 & 0.5913 & 0.38975 & 0.6521 & 0.17077 & 0.20794 & 0.002593 \\
水位 & 0.5510 & 0.29104 & 0.7379 & 0.17706 & 0.18758 & -0.022722 \\
水温 & -0.4958 & 0.72219 & 0.4440 & 0.01422 & -0.16355 & -0.006626 \\
最高气温 & -0.4426 & 0.68330 & 0.1113 & 0.37351 & 0.13130 & -0.405197 \\
最低气温 & -0.2333 & 0.75561 & 0.2602 & 0.01433 & -0.14161 & -0.307923 \\
气压 & -0.1198 & -0.63381 & -0.2365 & -0.15860 & 0.58922 & 0.387941 \\
降雨量 & 0.3217 & 0.08843 & 0.1950 & -0.79369 & 0.01859 & -0.430628 \\
\hline
\end{tabular}

与西江肇庆江段监测分析结果 ${ }^{[11]}$ 相比, 东江古竹江段鱼类产卵繁殖对水文生态因子的响应程度较低, 二维排序水温与径流量向量角度几乎垂直,而在西江肇庆江段的分析中,水温与径流量向量接近重叠,鱼类 产卵繁殖与水文生态更为关联. 东江古竹江段上游分布有新丰江以及枫树坝 2 个大型水库, 调节库容分别 为 $64.9 \times 10^{8} 、 12.5 \times 10^{8} \mathrm{~m}^{3}$, 相对多年平均总径流量为 $238 \times 10^{8} \mathrm{~m}^{3}$ 的东江来说, 具有强大的调节能力; 西江 肇庆江段的鱼苗来源主要在长洲坝水利枢纽以上的浔江、黔江江段,产卵场位置离上游最近水坝的距离都 超过 $100 \mathrm{~km}$, 肇庆江段采样点离长洲坝水利枢纽约 $200 \mathrm{~km}$. 尽管西江江段水坝对水文节律有影响,但远比东 江江段的小. 这说明东江江段鱼类对水文生态响应紊乱,群落结构已经失衡.

\section{2 梯级水坝是否导致外来种的暴发性增长}

尼罗罗非鱼作为一个引进的优良品种, 带来了良好的经济价值, 但其毕竟是外来物种, 对地方品种及环 境存在生态风险. 本文结果显示尼罗罗非鱼在东江古竹江段有暴发性繁殖现象, 尽管其繁殖高峰出现在 10 月份的原因尚不明了, 但从数量比例及生物量上综合考虑, 尼罗罗非鱼鱼苗是东江鱼苗的优势种之一, 东江 已经面临外来种的严峻威胁. 由于罗非鱼生长快、性成熟早、有护幼行为、适应性强, 其逃逸到自然水体后, 有严重生态影响, 如卢旺达共和国 Luhondo 湖 1935 年引进尼罗罗非鱼, 到 1952 年发现当地原有的 3 个鲤科 种类基本消失 ${ }^{[21]}$.

本文关注的是东江梯级水坝的修建是否导致罗非鱼的过度繁殖. 目前东江古竹江段洄游性鱼类(如青、 草、鲢、鳙等) 的鱼苗缺失, 其主要原因可能是梯级水坝阻隔了鱼类的洄游, 不能形成一定规模的繁殖群体. 这样在生态位上腾出了空间, 为其它种类侵人提供了机会; 另外, 水坝提高了库区水位, 为罗非鱼的越冬提 供了场所. 因此可以认为,东江梯级水坝的修建是导致罗非鱼成功人侵的原因之一. 但罗非鱼在东江江段暴 发性繁殖可能与水文节律及其性腺发育规律有关, 建议进行深人研究, 以便从其机理着手采取有限措施控 制罗非鱼种群过度扩张.

\section{3 东江江段鱼类增殖放流品种建议}

根据目前东江鱼类产卵状况监测, 原有的四大家鱼产卵场消失. 由于水坝的影响, 恢复四大家鱼 (青、 草、鲢、鳙) 产卵场的可能性很小, 因为根据四大家鱼产卵繁殖的条件需求, 受精卵需要数百公里的漂程才能 孵化出膜完成发育. 因此建议放流四大家鱼, 特别是鲢、鳙更应该作为东江鱼类人工放流的主要品种之一, 因为鲢、鳙为滤食性, 可以大量滤食浮游生物, 对河流营养物质及能量的控制及输出有重要作用. 鲢、鳙的下 行效应在武汉东湖水华控制以及云南滇池蓝藻治理上都有成功应用的例证.

广东鲂目前是珠江中下游优势种类 ${ }^{[22-23]}$, 充分说明了其具有良好的生态适应性,但在东江古竹江段尚 未采集到其鱼苗. 广东鲂鱼苗个体较为强壮、杂食性、生态位较宽、繁殖对生态水文需求也不苛刻, 种群恢复 起来难度相对较小. 因此广东鲂也建议作为东江鱼类人工放流的主要品种之一.

\section{4 鱼类洄游通道贯通必要性}

本次调查结果表明原有的东川江段四大家鱼产卵场已经消失, 目前在东江古竹以上江段也没有三角鲂 产卵场的分布, 说明了梯级水坝严重影响洄游性鱼类正常的生活史,东江下游江段及珠江三角洲栖息、育肥 的成熟亲鱼难以上溯. 已经修建的水坝都没有配套的过鱼通道, 尽管在洪水期,水坝在运行上可能会打开泄 
洪闸, 实施泻洪, 但洪峰的时间一般都很短, 即使鱼类可以在此期间上溯过坝, 其比例也很小. 从生态修复的 角度考虑, 有必要在东江各水坝上补建过鱼通道, 保障鱼类洄游通道畅通, 这对东江鱼类资源保护具有重要 意义.

\section{4 参考文献}

［1］珠江水系渔业资源调查编委会.珠江水系渔业资源调查研究报告:第一分册. 1985:409-457.

[2] 黄家明,赵会宏,李 羽等. 新丰江水库鱼类资源调查. 华南农业大学学报,2007,28(增刊) :22-26.

[ 3 ] 赵会宏,崔 科,甘 炼等. 东江鱼类资源调查结果初报. 华南农业大学学报,2007,28(增刊) :52-56.

[4] 刘 毅,林小涛,孙 军等. 东江下游惠州河段鱼类群落组成变化特征. 动物学杂志, 2011,46(2):1-11.

[ 5 ] 周春生,梁秩壆, 黄鹤年. 兴修水利枢纽后汉江产漂流性卵鱼类的繁殖生态. 水生生物学集刊, 1980,7 (2): 175-188.

[6]余志堂, 邓中粦, 许蕴轩等. 葛洲坝水利枢纽兴建后长江干流四大家鱼产卵场的现状及工程对家鱼繁殖影响的评 价. 见: 葛洲坝水利枢纽与长江四大家鱼. 武汉: 湖北科学技术出版社,1988:47-68.

[ 7 ] 李修峰, 黄道明, 谢文星等. 汉江中游产漂流性卵鱼类产卵场的现状. 大连水产学院学报, 2006,21(2): 105-111.

[ 8 ] 谭细畅,李新辉,陶江平等. 西江肇庆江段鱼类早期资源时空分布特征研究. 淡水渔业,2007,37(4) :37-40.

[ 9 ] 谭细畅, 李新辉, 林建志等. 珠江肇庆江段赤眼䲡早期发育形态及其补充群体状况. 华中农业大学学报: 自然科学 版,2009,28(5):609-613.

[10］谭细畅,李跃飞,赖子尼等. 西江肇庆江段鱼苗群落结构特征及及其周年变化. 水生态学杂志,2010,3(5):27-31.

[11] Tan XC, Li XH, Sovan L et al. Fish larvae annual dynamics and relationship with hydrological variation in the Pearl River. Environmental Biology of Fishes, 2010,88:217-225.

[12］李跃飞,李新辉,谭细畅等. 珠江中下游鲮早期资源分布规律. 中国水产科学,2010,18(1):171-177.

[13] 段辛斌,陈大庆, 李志华等. 三峡水库蓄水后长江中游产漂流性卵鱼类产卵场现状. 中国水产科学, 2008,15 (4): 524-532.

[14] Paukert CP, Fisher WL. Spring movements of paddlefish in a prairie reservoir system. Journal of Freshwater Ecology, $2001, \mathbf{1 6}(1): 113-124$.

[15] Rogério NC, Samara HS, David RT et al. Distribution and abundance of fish eggs and larvae in three tributaries of the Upper Uruguay River (Brazil). Environmental Biology of Fishes, 2010, 91(1) :51-61.

[16] 钟 麟. 家鱼的生物学和人工繁殖. 北京:科学出版社, 1965:39.

［17］曹文宣,常剑波,乔 晔等. 长江鱼类早期资源. 北京:中国水利水电出版社, 2007:52-252.

[18] 易伯鲁,梁秩菜, 余志堂等. 长江草、青、鲢、鲔四大家鱼早期发育的研究. 见: 葛洲坝水利枢纽与长江四大家鱼. 武 汉:湖北科学技术出版社,1988:69-112.

[19] 梁秩笨. 西江常见鱼类早期发育的分类鉴定及其产卵类型. 见: 珠江水系渔业资源调查编委会编. 珠江水系渔业资 源调查研究报告:第四分册. 1985:255-295.

[20] Ter Braak CJF. Canonical correspondence analysis: a new eigenvector technique for multivariate direct gradient analysis. Ecology, 1986,67:1167-1179.

[21] Lus DV, Snoeks J, Thys van den Audenaerde DFE. The effects of Tilapia introductions in Lake Luhondo, Rwanda. Environmental Biology of Fishes, 1990, 27 : 303-308.

[22］李跃飞,李新辉,谭细畅等. 西江肇庆江段渔业资源现状及其变化. 水利渔业,2008,28(2):80-83.

[23] 李 捷,李新辉,谭细畅等. 广东肇庆西江珍稀鱼类省级自然保护区鱼类多样性. 湖泊科学, 2009,21 (4):556-562. 